\title{
Association of Health Literacy and Glycemic Control in Type-2 Diabetic Patients
}

${ }^{1}$ Hala Bashir Hashmi, ${ }^{2}$ Hina Mahmood, ${ }^{3}$ Rabbiya Sarwar, ${ }^{2}$ Fizza Anwar,

${ }^{4}$ Ayesha Humayun

${ }^{1}$ Department of Community Medicine, Quaid-e-Azam Medical College, Bahawalpur

${ }^{2}$ Department of Community Medicine, CMH Medical College \& Institute of Dentistry, Lahore

${ }^{3}$ Department of Community Medicine, University College of Medicine \& Dentistry, Lahore

${ }^{4}$ Department of Public Health \& Community Medicine, Shaikh Khalifa Bin Zayed Al-Nahyan Medical College

\begin{abstract}
Introduction: Health literacy is the new evolving concept in last few decades as an ability of an individual to understand the health and health related events and its utilization for better health outcome. Inadequate health literacy leads to increased burden of chronic diseases like diabetes mellitus. Aims \& Objectives: To determine the association of health literacy and glycemic control in type 2 diabetic patients.

Place and duration of study: This study was conducted at the Diabetes Clinic of Shaikh Zayed Outpatient Department, Lahore from July to Sept 2016.Material \& Methods: Type 2 diabetic patients coming to the Outpatient Department of Shaikh Zayed Hospital Lahore were enrolled for the study. Health literacy assessment tool was constructed for type 2 diabetic patients who could understand the Urdu language. The tool was context specific; it was validated and applied on 135 diabetic patients, visiting the Diabetes Clinic of Outpatient Department of Shaikh Zayed hospital Lahore, for their regular check-up. All patients diagnosed with type 2 diabetes were included in the study. Results: $43 \%$ patients had inadequate health literacy level and $82.2 \%$ of the patients had poor glycemic control level (HbAlc $>7 \%)$. Health literacy was found significantly associated with glycemic control $(\mathrm{p}=.002)$. Sociodemographic factors like gender $(\mathrm{p}=.001)$ and economic status $(\mathrm{p}=.003)$ were also found to be statistically associated with health literacy. Conclusion: patients with inadequate health literacy level had poor glycemic control.
\end{abstract}

Key words: Health Literacy, Health Literacy Assessment, Glycosylated Hemoglobin, HbA1c, Glycemic Control.

\section{INTRODUCTION}

$\mathrm{H}$ ealth literacy means skills that are required to function effectively in health care system. ${ }^{1}$ Health care professionals provide information to the patients about their health and utilization of health facilities either in written, verbal or in visual forms and results shows that health literacy can be improved if good communicating medium is used. ${ }^{2}$ Health system plays a significant role in improving literacy level as health literacy is not only the ability to get information but it also includes proper communication skills between health care providers and patients. ${ }^{3}$ Most of the adults can easily understand the health information if it is provided either through verbal or visual presentation. Audios and videos are helpful in understanding difficult information and they can also increase the compliance. $^{4}$
There are three types of health literacy: functional, interactive and critical skills. Functional health literacy is the ability to read and write health information and the skills that are required to interpret the information and make decisions for better outcome. ${ }^{5}$ Health literacy measuring tools have been developed but there is no single tool that is applicable for all cultures that are having different languages and social influence on their health. In order to develop a measuring scale for health literacy, the tool should include health related context. $^{6}$ There are two domains of Health literacy that are reported by institute of medicine (IOM), which includes print literacy and oral literacy related to health information provided to patients. The understanding depends upon reading and listening skills and the culture and social norms. ${ }^{7}$ At present no valid tool has been identified which can be used globally. For evaluation of health literacy in American adults, Test of functional health literacy 
of adults (TOFHLA) is used but it is a time consuming test. ${ }^{8}$ Those who are scoring adequate functional health literacy are able to read and understand the medical terms, prescription and schedule of medication. Those who have marginal or inadequate level of Health literacy seek help from Health professionals. ${ }^{9}$ Literacy skills can also be determined by self-reporting from the patient. ${ }^{10}$ These Health literacy tools have been translated in English and Spanish speaking adults (s-TOFHLA), Portuguese (s-HATFPA-18) and Chinese languages (NVS). Still there are many challenges for Health literacy assessment tools for validity and acceptability. Functional Health literacy cannot only be evaluated on a single parameter of reading ability. The common language in which patient can communicate with Health provider is the better way of assessment. ${ }^{11}$ Health providers are reluctant to screen patients for their literacy level as it may reflect problem in health system and also indicate their lack of training. ${ }^{12}$ The Health literacy tools that have been developed might not be applicable in all clinical settings, so certain criteria should be followed to make literacy tool applicable in clinical and research side. ${ }^{13}$ Those who are living in developing countries have different cultures and every person is not literate, so health literacy evaluation might be done in different domains derived from their own culture and languages.

Poor glycemic control is associated with inadequate health literacy level. ${ }^{14}$ Diabetic outcomes can be poor due to lower health literacy level. Low health literacy results into more visits to health care settings, as people seek more guidance from health care providers which might be a cause of burden on outpatient departments. ${ }^{15}$ A study showed that poor glycemic control (HbAlc $>7 \%)$ is significantly associated with low literacy levels. ${ }^{16}$ A study done demonstrated that inadequate literacy causes increased risk of diabetic complications. ${ }^{17}$

Diabetes and its complications are highly prevalent in Pakistan as it is ranking fourth among countries where diabetes prevalence is increasing. ${ }^{18}$ This increase in burden of disease is the result of low literacy level, less awareness, improper utilization of health facilities and low health literacy level. No proper work has been done in Pakistan on the determination of health literacy level; this might be due to the cultural barrier as no tool for health literacy could be implemented. The health literacy assessment tool can be developed and implemented according to the cultural and language requirement of a certain community and these can be context specific to determine the health outcomes. ${ }^{19}$
This study aims to find out association of health literacy and glycemic control through selfconstructed health literacy assessment tool for population who can understand Urdu language.

\section{MATERIAL AND METHODS}

A cross-sectional study was done on 135 patients with type 2 diabetes, coming for their regular checkup in diabetic clinic of Shaikh Zayed outpatient department, Lahore.

Inclusion criteria: Patients of both gender and all ages with known diabetes for last 1-10 years and with documented $\mathrm{HbA} 1 \mathrm{c}$ level during last 6 months, were recruited in study through consecutive sampling, a type of non-probability sampling.

A predetermined set of information was used to develop a self-constructed Urdu questionnaire/tool for assessment of health literacy through assessment of the level of understanding of Pakistani population who can understand Urdu language. The face, content and construct validity of questions were assessed by field experts and reliability of the tool was determined by Cronbach alpha that was 0.84 . Ethical approval of the study was taken formally from Institutional review Board of Shaikh Zayed Medical Complex. Patients were interviewed separately to ensure privacy and in case of opposite gender, an attendant was allowed to sit with them after taking written informed consent. Assessment of Health literacy was done by administering listening and visual sessions in Urdu, followed by assessment of their understanding of the messages conveyed to them. Health literacy was assessed as inadequate (0-3), adequate (7-10) and moderate (46) through a scoring. Health literacy level, age, gender, occupation, education were independent variables of the study and glycemic control level $($ good $=$ HbAlc $<7$, poor $=$ HbAlc $>7)$ was a dependent variable. Data was analyzed by chisquare statistical test and multiple regression method was used to determine the association between health literacy and glycemic control.

\section{RESULTS}

The number of the participants for the study was 135, of whom $71(52.6 \%)$ were female $(\mathrm{F})$ and 64 (47.4\%) were male. Among 71 females, $51.1 \%$ were house wives, $20.7 \%$ patients were running different kind of businesses, $18.5 \%$ were doing job, $5.2 \%$ of patients were laborers and $3 \%$ male were retired. $40.7 \%$ patients had duration of diabetes $\leq 5$ years and $59.3 \%$ patients had duration of diabetes $>5$ years after being diagnosed clinically. The 
participants ranged in age from 30 to 65 years, with a mean age of $50.96 \%$ years $(\mathrm{SD}= \pm 7.48 \%)$. The participants were divided among five-year categories. $3.0 \%$ were $30-37$ years of age, $12 \%$ were $38-44$ years of age, $35.6 \%$ patients were $45-51$ years of age, $32.6 \%$ were $52-58$ years of age group and $16.3 \%$ were $59-65$ years of age. When considering their formal education, it revealed that $23 \%$ were illiterate, $24.4 \%$ did matriculation, $29.6 \%$ had primary level, $8.9 \%$ had higher secondary level of education and $14 \%$ completed their graduation (Table-1).

$43 \%$ patients had inadequate health literacy. $37 \%$ of patients had moderate health literacy level while $20 \%$ had adequate health literacy. $17.8 \%$ patients had good glycemic control and $82.2 \%$ had poor glycemic control (Table-1).

Chi-square test showed that there is significant difference between health literacy and glycemic control (Table-2). Logistic regression analysis was used to examine the association between patient glycemic control and health literacy level with other five covariates showing only health literacy level was significantly associated with glycemic control $\left(\mathrm{R}^{2}=17.2 \%\right)$. Health literacy level having a greater association with glycemic control $\mathrm{P}=.002$ $(\mathrm{OR}=14.3 \%)$ with $95 \% \mathrm{CI}(0.41-0.505)$.

\begin{tabular}{|c|c|c|c|c|}
\hline Chara & $\begin{array}{l}\text { Adequate } \\
\text { health } \\
\text { literacy N } \\
(\%)\end{array}$ & $\begin{array}{l}\text { Moderate } \\
\text { health } \\
\text { literacy N } \\
(\%)\end{array}$ & $\begin{array}{l}\text { Inadequate } \\
\text { health } \\
\text { literacy N } \\
(\%)\end{array}$ & $\begin{array}{l}p \text {-value } \\
(\leq 0.05)\end{array}$ \\
\hline $\begin{array}{l}\text { Gender } \\
\text { Male } \\
\text { Female }\end{array}$ & $\begin{array}{l}17(26.6) \\
10(14.1)\end{array}$ & $\begin{array}{l}30( \\
20(\end{array}$ & $\begin{array}{l}17(26.6) \\
41(57.7)\end{array}$ & 0.001 \\
\hline $\begin{array}{l}\text { Age (years) } \\
30-50 \\
51-65\end{array}$ & $\begin{array}{l}6(28.6) \\
21(18.4)\end{array}$ & $\begin{array}{l}10( \\
40\end{array}$ & $\begin{array}{l}5(23 \\
53(4\end{array}$ & 0.15 \\
\hline $\begin{array}{l}\begin{array}{l}\text { Duration of } \\
\text { diabetes }\end{array} \\
1-5 \text { years } \\
6-10 \text { years } \\
\end{array}$ & $\begin{array}{l}14 \\
13 \\
\end{array}$ & $\begin{array}{l}21 \\
29 \\
\end{array}$ & $\begin{array}{l}20 \\
38 \\
\end{array}$ & 0.308 \\
\hline $\begin{array}{l}\text { Diabetes } \\
\text { control } \\
\text { Good } \\
\text { Poor }\end{array}$ & $\begin{array}{l}11(45.8) \\
16(14.4)\end{array}$ & $\begin{array}{l}7(29.2) \\
43(38.7)\end{array}$ & $\begin{array}{l}6(25) \\
52(46.8)\end{array}$ & 0.002 \\
\hline $\begin{array}{l}\text { Education } \\
\text { Literate } \\
\text { Illiterate } \\
\end{array}$ & $\begin{array}{l}19(28.4) \\
8(12.9) \\
\end{array}$ & $\begin{array}{l}29(40.3) \\
21(33.9) \\
\end{array}$ & $\begin{array}{l}24(33.3) \\
33(56.9) \\
\end{array}$ & 0.099 \\
\hline $\begin{array}{l}\text { Economic } \\
\text { status } \\
\text { Dependent } \\
\text { Independent }\end{array}$ & $\begin{array}{l}9(12.2) \\
18(29.5)\end{array}$ & $\begin{array}{l}24(32.4) \\
26(42.6)\end{array}$ & $\begin{array}{l}41(55.4) \\
17(27.9)\end{array}$ & 0.003 \\
\hline
\end{tabular}

Table-1: Socio-demographics and health literacy level among type 2 diabetic patients

\begin{tabular}{|c|c|c|c|}
\hline Characteristics & $\begin{array}{l}\text { Good glycemic } \\
\text { control N (\%) }\end{array}$ & $\begin{array}{l}\text { Poor glycemic } \\
\text { control N (\%) }\end{array}$ & $\begin{array}{c}\text { p-value } \\
(\leq 0.05)\end{array}$ \\
\hline \begin{tabular}{|l} 
Gender \\
Male \\
Female \\
\end{tabular} & $\begin{array}{l}10(15.6) \\
14(19.7)\end{array}$ & $\begin{array}{l}54(84.4) \\
57(80.3)\end{array}$ & 0.535 \\
\hline \begin{tabular}{|l} 
Age (years) \\
$30-50$ \\
$51-65$ \\
\end{tabular} & $\begin{array}{l}4(19) \\
20(17.5)\end{array}$ & $\begin{array}{l}17(81) \\
94(82.5)\end{array}$ & 0.868 \\
\hline \begin{tabular}{|l|}
$\begin{array}{l}\text { Duration of } \\
\text { diabetes }\end{array}$ \\
$1-5$ years \\
$6-10$ years \\
\end{tabular} & $\begin{array}{l}13(23.6) \\
11(13.8)\end{array}$ & $\begin{array}{l}42(76.4) \\
69(59.3) \\
\end{array}$ & 0.140 \\
\hline \begin{tabular}{|l|} 
Health literacy \\
level \\
Adequate \\
Moderate \\
Inadequate \\
\end{tabular} & $\begin{array}{l}11(40.7) \\
7(14) \\
6(10.3) \\
\end{array}$ & $\begin{array}{l}16(59.3) \\
43(86) \\
52(83.9)\end{array}$ & 0.002 \\
\hline \begin{tabular}{|l|} 
Education \\
Literate \\
Illiterate \\
\end{tabular} & $\begin{array}{l}14(19.4) \\
10(16.1) \\
\end{array}$ & $\begin{array}{l}58(80.6) \\
52(83.9) \\
\end{array}$ & 0.791 \\
\hline $\begin{array}{l}\text { Economic status } \\
\text { Dependent } \\
\text { Independent }\end{array}$ & $\begin{array}{l}13(17.6) \\
11(18)\end{array}$ & $\begin{array}{l}61(82.4) \\
50(82)\end{array}$ & 0.94 \\
\hline
\end{tabular}

Table-2: Characteristics of patients and glycemic control

\section{DISCUSSION}

Forty-seven percent of the patients were male and fifty-three percent were female. This number of males and females does not reflect the incidence of diabetes mellitus in the general population; it is likely to represent the attendance at the diabetes clinic in the outpatient department of Shaikh Zayed hospital. Among 30 to 65 years old diabetic patients the mean age of patients was 50.96 years. Statistics have shown that currently $5.1 \%$ adults in the world are suffering from diabetes and if the current trend continues by 2025 this percentage will increase upto $6.3 \% .{ }^{20}$ It is emphasized to start population based programs for its prevention and coordinated efforts for its control are much needed. ${ }^{21}$

Descriptive analysis showed that the mean health literacy level of diabetic patients was 8.41 with $43 \%$ scoring inadequate level. These results are close to, as reported by Souza et al who studied a sample of Brazilian type 2 diabetic adults and showed 56.6\% of sample had below adequate health literacy level. ${ }^{14}$

The mean glycemic control level of patients was 1.822 with $82.2 \%$ of patients having poor glycemic control level. It showed association with health literacy level with $\mathrm{p}=.002 \%$ but no significant association was found with other socio-demographic factors. Logistic regression results showed that patients with poor glycemic control had inadequate health literacy level with 0.14 of odds ratio. Among English and Spanish speaking adults it was found 
that patients with inadequate health literacy level were more likely to have poor glycemic control level and were at higher rates of developing complications of their disease. ${ }^{17}$ Also another study in Brazil supports same results of association of inadequate health literacy of type 2 adults with poor glycemic control. ${ }^{14}$ The statistical analysis showed that poor glycemic control level was not associated with formal education level of patients $(\mathrm{p}=.791)$; it means that illiterate patients are able to manage their health somehow either with their self-management skills or with the help of health professionals.

There are certain limitations of this study that should be mentioned here. As this study was conducted only in one diabetic clinic of outpatient department so it might not be able to generalized to whole population of Pakistan. Patients coming to a government hospital were included so the patients visiting private sector were missed. This study is unique and is providing a path for future researches on improving and addressing health illiteracy for the improvement of self-care in diabetes and other chronic diseases.

\section{CONCLUSION}

Health illiteracy was found to be associated with poor glycemic control among low and middle class patients. Self-care is essential in diabetes so health literacy can help improve patient compliance to treatment, lifestyle change and nutritional modification. It is concluded that better health literacy can improve glycemic control among diabetics hence helping them to practice self-care effectively. Health literacy improvement activities should be conducted to improve understanding of patients so they become more compliant and this in turn reduces burden on health system.

\section{REFERENCES}

1. Berkman ND, Sheridan SL, Donahue KE, Halpern DJ, Crotty K. Ann Intern Med. 2011 Jul $19 ; 155(2): 97-107$.

2. Institute of Medicine (US) Committee on Health Literacy; Nielsen-Bohlman L, Panzer AM, Kindig DA, editors. Health Literacy: A Prescription to End Confusion. Washington (DC): National Academies Press (US); 2004. 6, Health Systems. Available from: https://www.ncbi.nlm.nih.gov/books/NBK2160 31/

3. Berkman ND, Davis TC, McCormack L. Health Literacy: What Is It? J Health Commun. 2010 Aug 31; 15(sup2):9-19.
4. Chen Y, Chalmers I. Testing treatments interactive (TTi): helping to equip the public to promote better research for better health care. J Evid Based Med. 2015;8(2):98-102.

5. Sørensen K, Van den Broucke S, Fullam J, Doyle G, Pelikan J, Slonska Z, et al. Health literacy and public health: A systematic review and integration of definitions and models. BMC Public Health. 2012; 12:80.

6. Pleasant A, McKinney J, Rikard RV. Health Literacy Measurement: A Proposed Research Agenda. J Health Commun. 2011 Sep 30; 16(sup3):11-21.

7. Squiers L, Peinado S, Berkman N, Boudewyns $\mathrm{V}$, McCormack L. The health literacy skills frame work. $J$ Health Commun. 2012; 17(sup3):30-54.

8. Schillinger, Lauren RB, Andrew JK, Frances W, Nancy A. Public Health Rep. 2006 May-Jun; 121 (3): 245-254.

9. Kindig DA, Panzer AM, Nielsen-Bohlman L. Health literacy: a prescription to end confusion: National Academies Press; 2004.

10. Literacy I of M (US) C on H, Nielsen-Bohlman L, Panzer AM, Kindig DA. The Extent and Associations of Limited Health Literacy [Internet]. National Academies Press (US); 2004 [cited 2017 Jan 27]. Available from: https://www.ncbi.nlm.nih.gov/books/NBK2160 36/

11. Paasche-Orlow MK, Wolf MS. Promoting health literacy research to reduce health disparities. J Health Commun.2010;15(S2):34-41

12. Calderón JL, Shaheen M, Hays RD, Fleming ES, Norris KC, Baker RS. Improving Diabetes Health Literacy by Animation. Diabetes Educ. 2014 May 1; 40(3):361-72.

13. Paasche-Orlow MK, Wolf MS. Promoting health literacy research to reduce health disparities. Journal of health communication. 2010;15(S2):34-41.

14. Souza JG, Apolinario D, Magaldi RM, Busse AL, Campora F, Jacob-Filho W. Functional health literacy and glycaemic control in older adults with type 2 diabetes: a cross-sectional study. BMJ Open. 2014 Feb 1;4(2):e004180.

15. Berkman ND, Sheridan SL, Donahue KE, Halpern DJ, Crotty K. Low health literacy and health outcomes: an updated systematic review. Ann.Intern.Med. 2011;155(2):97-107.

16. Chen G-D, Huang C-N, Yang Y-S, Lew-Ting $\mathrm{C}-\mathrm{Y}$. Patient perception of understanding health education and instructions has moderating effect on glycemic control. BMC public health. 2014; 14(1):683. 
17. Bailey SC, Brega AG, Crutchfield TM, Elasy T, Herr H, Kaphingst K, et al. Update on health literacy and diabetes. Diabetes Educ. 2014; 40(5):581-604.

18. John AS, Davis WA, Price CP, Davis TME. The value of self-monitoring of blood glucose: a review of recent evidence. $J$ Diabetes Complicat. 2010 Mar 1; 24(2):129-41.

19. Bohlman LN. Read "Health Literacy: A Prescription to End Confusion" at NAP.edu [Internet]. 2004 [cited 2017 Jan 4]. Available from:

https://www.nap.edu/read/10883/chapter/1

20. Atlas D. International diabetes federation. IDF Diabetes Atlas, 7th edn Brussels, Belgium: IDF. 2015.

21. Hakeem R, Fawwad A. Diabetes in Pakistan: epidemiology, determinants and prevention. J Diabetol. 2010; 1(3):3.

\section{The Authors:}

Dr. Hala Bashir Hashmi

Demonstrator

Department of Community Medicine,

Quaid-e-Azam Medical College, Bahawalpur.

Dr. Hina Mahmood

Assistant Professor,

Department of Community Medicine,

CMH Medical College \& Institute of Dentistry,

Lahore.
Dr. Rabbiya Sarwar

Senior Demonstrator,

Department of Community Medicine,

University College of Medicine \& Dentistry,Lahore.

\section{Dr. Fizza Anwar}

Demonstrator,

Department of Community Medicine,

CMH Medical College \& Institute of Dentistry,

Lahore.

Dr. Ayesha Humayun

Professor \& HOD,

Department of Public Health \& Community Medicine,

Shaikh Khalifa Bin Zayed Al-Nahyan Medical

College, Lahore

\section{Corresponding Author:}

Dr. Hina Mahmood

Assistant Professor,

Department of Community Medicine,

CMH Medical College \& Institute of Dentistry,

Lahore.

E-mail: hinausman_ar@hotmail.com 